OPEN ACCESS

Edited by:

Egor Plotnikov,

Belozersky Institute

of Physico-Chemical Biology,

Lomonosov Moscow State University,

Russia

Reviewed by:

Jorge L. Gamboa,

Vanderbilt University Medical Center,

United States

Hirotaka Komaba,

School of Medicine, Tokai University,

Japan

Gaia Gherardi,

University of Padua, Italy

*Correspondence:

Reiko Inagi

inagi-npr@umin.ac.jp

Specialty section:

This article was submitted to Renal and Epithelial Physiology,

a section of the journal

Frontiers in Physiology

Received: 23 May 2020

Accepted: 12 August 2020

Published: 04 September 2020

Citation:

Takemura $K$, Nishi $\mathrm{H}$ and Inagi $\mathrm{R}$ (2020) Mitochondrial Dysfunction

in Kidney Disease and Uremic

Sarcopenia

Front. Physiol. 11:565023. doi: 10.3389/fphys.2020.565023

\section{Mitochondrial Dysfunction in Kidney Disease and Uremic Sarcopenia}

\author{
Koji Takemura ${ }^{1}$, Hiroshi Nishi' ${ }^{1}$ and Reiko Inagi2* \\ ${ }^{1}$ Division of Nephrology and Endocrinology, Graduate School of Medicine, The University of Tokyo, Tokyo, Japan, ${ }^{2}$ Division \\ of CKD Pathophysiology, Graduate School of Medicine, The University of Tokyo, Tokyo, Japan
}

Recently, there has been an increased focus on the influences of mitochondrial dysfunction on various pathologies. Mitochondria are major intracellular organelles with a variety of critical roles, such as adenosine triphosphate production, metabolic modulation, generation of reactive oxygen species, maintenance of intracellular calcium homeostasis, and the regulation of apoptosis. Moreover, mitochondria are attracting attention as a therapeutic target in several diseases. Additionally, a lot of existing agents have been found to have pharmacological effects on mitochondria. This review provides an overview of the mitochondrial change in the kidney and skeletal muscle, which is often complicated with sarcopenia and chronic kidney disease (CKD). Furthermore, the pharmacological effects of therapeutics for CKD on mitochondria are explored.

Keywords: mitochondria, CKD - chronic kidney disease, sarcopenia, kidney, skeletal muscle

\section{INTRODUCTION}

Mitochondria originated approximately 1.5 billion years ago from $\alpha$-proteobacterium via symbiosis within an ancestral eukaryotic host cell. Although mitochondria contain double membrane and serve as the main producer of adenosine triphosphate (ATP), their form and composition have evolved, and these organelles have gained a myriad of additional functions. This article reviews mitochondrial functions, the changes of these organelles in the kidney (Figure 1A) and skeletal muscle tissues (Figure 1B) in kidney diseases, and the potential effects of therapeutic agents on the mitochondria in treating kidney diseases and uremic sarcopenia.

\section{MITOCHONDRIA BIOLOGY IN THE KIDNEY}

\section{Mitochondrial Structure}

Mitochondria are intracellular organelles found in all eukaryotes. The mitochondrial structure contains a membrane structure of outer and inner mitochondria membrane (IMM) layers, with one compartment between the intermembrane space and the inner matrix. The mitochondrial outer mitochondria membrane (OMM) contains a porin that controls the transport of proteins into mitochondria and allows non-selective permeation of small molecule substances of approximately $1,550 \mathrm{kDa}$. The IMM contains a complex folded structure, the cristae, that contributes to oxidative phosphorylation to produce ATP, which is an energy source in the cell.

The renal proximal tubules contain more mitochondria than any other compartments in the kidney. Renal proximal tubules absorb more than $65 \%$ of the filtrate that passes through the glomerular membrane filter, such as glucose, ions, and albumin (Rector, 1983). Mitochondria often undergo transformation in both physiological and pathological conditions (Wakabayashi, 2002). 
In a diseased kidney, premorse and gigantic mitochondria are noted in the cytoplasm of the proximal epithelial cells, as shown in early studies of human kidney samples using electron microscopy (Suzuki et al., 1975). The experimental literature also supports that mitochondria amounts largely diminish and their structure appears altered after acute kidney injury (AKI) (Lan et al., 2016). Although the molecular mechanism underlying the morphologic alteration has yet to be investigated, mitochondria represent one of the more vulnerable organelles for various types of toxic and pathogenic insults.

\section{Mitochondrial Chromosome, Genome, DNA \\ Mitochondrial Biogenesis}

The mitochondrial mass is increased through the cellular process called mitochondrial biogenesis to adapt to the ever-changing energy demand. Mitochondrial biogenesis leads to a greater mitochondrial metabolic capacity by increasing synthesis of metabolic enzymes. While the majority of mitochondrial molecules are encoded by the cell nuclear genes, most parts of the electron transport chain (ETC) that function as an energy generator are produced from mitochondrial genes. Mitochondrial DNA (mtDNA) is transcribed by the mitochondrial DNA-directed RNA polymerase, POLRMT (Graziewicz et al., 2006) and the essential enhancer is the mitochondrial transcription factor A (TFAM), which ensures mtRNA unwinding and flexing required for the POLRMT binding to the promoters. The expression of TFAM is regulated by nuclear respiratory factor 1 (Nrf1) binding to the specific promoter sites (Virbasius and Scarpulla, 1994; Gureev et al., 2019), suggesting that Nrf1 may be involved the biogenesis and energy production in the mitochondria (van Tienen et al., 2010; Benner et al., 2013). Also, researchers have discovered that peroxisome proliferator-activated receptor $\gamma$ coactivator $1 \alpha$ (PGC- $1 \alpha)$ in brown adipocytes is a contributing factor for cold-mediated mitochondrial biogenesis (Puigserver et al., 1998). This transcription coactivator promotes the transcription of Nrf1 although PGC- $1 \alpha$ acts as a coactivator for numerous genes including $\mathrm{Nrf2}$ (Wu et al., 1999). PGC-1 $\alpha$ also activates mitochondrial biogenesis in skeletal muscle and enhances the slow-twitch manifestations of the skeletal muscle, such as fatty acid oxidation and an increase in type I myosin heavy chain (Wu et al., 1999; Jornayvaz and Shulman, 2010). Furthermore, this coactivator is important for skeletal muscle remodeling in physical exercise (Lira et al., 2010).

In sepsis-associated AKI, the mitochondrial function deteriorates, and the expression of genes involved in oxidative phosphorylation is reduced (Parikh et al., 2015). Particularly, PGC-1 $\alpha$ expression decreases as renal function declines, and renal function was impaired due to prolonged sepsis. The activation of PGC-1 $\alpha$ may promote recovery from AKI caused by sepsis, and this application in therapy is expected. Recently, our laboratory revealed that mtDNA copy number and PGC$1 \alpha$ expression were reduced in the kidneys of animals with polycystic kidney disease (Ishimoto et al., 2017). Moreover, the eradication of mitochondrion-specific oxidants reduced intracellular superoxide and halted the proliferation of cyst epithelial cells via extracellular signal-related kinase inactivation (Ishimoto et al., 2017).

\section{Mitochondrial DNA Leakage}

In cells infected with pathogens (e.g., DNA viruses), the pathogen-derived double-stranded DNA appears in the cytoplasm. Cyclic GMP-AMP synthase (cGAS) is a pattern recognition receptor that recognizes double-stranded DNA in the cytoplasm and then binds to the trans-membrane protein, a stimulator of interferon genes (STING) localized on the endoplasmic reticulum (ER). Eventually, this reaction induces a type I interferon-mediated host defense response to DNA viruses (Chen et al., 2016). Moreover, the cGAS-STING pathway activation is involved in autoimmune and inflammatory reactions, likely resulting from the activation of cGAS by self-genomic DNA damage (Li and Chen, 2018).

Our group recently clarified the relationship between mitochondrial damage and the induction of cGAS-STING pathway in inflamed proximal tubular cells. In cisplatin-induced AKI, the cGAS-STING pathway was activated in the kidney (Maekawa et al., 2019). In STING-deficient mice, cisplatininduced renal dysfunction and inflammatory responses were reduced. Additionally, the mitochondrial membrane potential was reduced in renal proximal tubular cells stimulated with cisplatin, and mtDNA leaked into the cytosol, thereby causing the activation of the cGAS-STING pathway (Maekawa et al., 2019). The inhibition of this pathway is a promising target for future treatments of AKI.

\section{Mitochondrial Dynamics}

Although mitochondrial biogenesis promotes new mitochondria production, mitochondria cannot be generated de novo. Instead, mitochondria form a dynamic network that can alter the shape and size and also add new content to pre-existing mitochondria. In other words, mitochondria actively and frequently undergo fusion and division (fission), such that long and extended structures are formed through fusion, and small fragmentation is induced through the division. Mitochondrial fusion is caused by several guanosine triphosphate hydrolases (GTPase), including mitofusin 1 (Mfn1), Mfn2, and optic atrophy 1 (Opa1). Both Mfn1 and Mfn2 are considered to contribute to OMM fusion, whereas Opal splicing contributes to IMM fusion. Conversely, mitochondrial fission is promoted by fission 1 protein (Fis1), that is localized on the OMM, and the GTPase, dynaminrelated protein (Drp1). The mutation of Drp1 is associated with lethal neonatal defects in humans (Waterham et al., 2007), and the mice deficient in Drp1 are also embryonic lethal, whereas brain-specific Drp1 ablation causes developmental defects to the cerebellum (Wakabayashi et al., 2009). These findings suggest that mitochondrial fission plays an essential role in early development and differentiation.

In ischemic and cisplatin nephrotoxic AKI, these mitochondrial dynamics have been analyzed mainly in proximal tubules that are dependent on oxidative phosphorylation for the large demand of ATP necessary for solute transportation. 


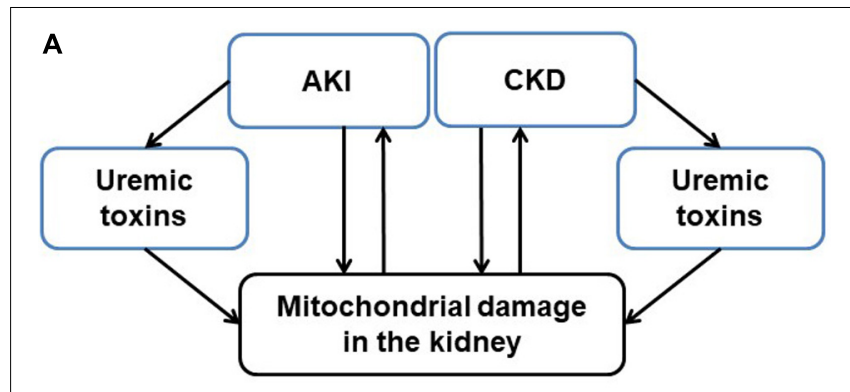

B

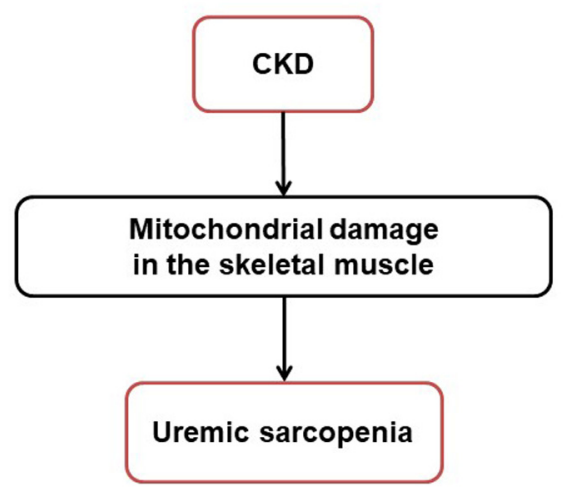

FIGURE 1 | Mitochondrial damage in CKD and uremic sarcopenia. (A) Stressors like sepsis, ischemia and toxins induce acute mitochondrial damage. Pathogenesis such as hypertension, diabetes, and obesity induce chronic mitochondrial damage. Uremic toxins accumulated in AKI and CKD also induce mitochondrial damage. On the other hand, mitochondrial damage itself exacerbates kidney damage, forming a vicious cycle in CKD progression. (B) In CKD, mitochondrial damage mediates uremic sarcopenia. AKI, acute kidney injury; CKD, chronic kidney disease; ROS, reactive oxygen species; ATP, adenosine triphosphate.

\section{Mitochondria and ER Crosstalk}

Eukaryotic cells contain various organelles besides the mitochondria. The functions of these individual organelles and the communication between them are essential for cell survival, proliferation, and differentiation. Intracellular transfer of vesicles enables communication between distant organelles via microtubules and actin along the cytoskeleton (Allan and Schroer, 1999; Bonifacino and Glick, 2004). Moreover, different organelles can also communicate with each other through direct contact and proximity signaling. The ER is located at the center of the membrane contact site (MCS) between organelles. Particularly, mitochondria-associated membranes (MAMs) have been intensively studied as a type of MCS formed through the ER (Fujimoto and Hayashi, 2011; Inoue et al., 2019). This machinery forms a raft-like structure rich in cholesterol and sphingolipids similar to caveola (Hayashi and Su, 2007) and enables molecular communications between ER and mitochondria via calcium, lipid synthases, inositol trisphosphate (IP3) receptors, and sarco/endoplasmic reticulum calcium-ATPases that are abundant and active on the MAM (Appenzeller-Herzog and Simmen, 2016). Notably, mitochondrial fission-promoting enzyme Mfn2 is located both in the mitochondria and partially in the ER. Furthermore, Mfn2 on the ER assembles a molecular complex with Mfn1 on the mitochondria that tightens the connection between ER and mitochondria (de Brito and Scorrano, 2008).

In the murine diabetic kidney, the MAM is significantly reduced and resembles the severity of tissue damage (Yang et al., 2019). Cultured tubular cells overexpressing the MAMuncoupling protein (UCP), FATE-1, are resistant to high-glucose stimuli and have less cellular apoptosis (Yang et al., 2019). Although the mitochondrial-ER association has only lately been highlighted (Inoue et al., 2019; Yang et al., 2020), how this organelle crosstalk is altered in AKI or chronic kidney disease (CKD) remains largely unknown.

\section{Energetics}

\section{Glycolysis and Tricarboxylic Acid (TCA) Cycle}

Glycolysis is considered the most primitive metabolic system. This process catabolizes glucose into organic acids, such as pyruvate, and produces energy for the organism to consume. Under aerobic conditions, pyruvate produced by glycolysis is transported from the cytosol to the mitochondrial matrix through an active transporter. It is next decarboxylated by the pyruvate dehydrogenase complex (PDHC) and then converted to acetylCoA (Semenza, 2011; Gray et al., 2014). The acetyl-CoA enters the TCA cycle, which oxidizes acetyl-CoA to produce carbon dioxide. TCA produces coenzymes as three molecules of $\mathrm{NADH}$, one molecule of $\mathrm{FADH}_{2}$, GTP. Although carbon dioxide is excreted outside the mitochondria and no ATP is produced in the TCA cycle, the resulting coenzymes aide ATP production in the subsequent oxidative phosphorylation.

In ischemic AKI, glucose metabolism is differently altered in the cortex and the medulla of the kidney. Metabolites pyruvate and lactate are decreased in the cortex during early onset of AKI, while the TCA intermediates succinate and malate 
are almost unchanged (Wei et al., 2014). These observations suggest a transient decrease in the use of glucose for energy metabolism in the cortex. By contrast, the kidney medulla showed a slower decrease in glycolysis and TCA cycle activity over time. Tubular cell glucose uptake and lactate production were accelerated in fibrotic kidney resembling human CKD, implying an enhancement of aerobic glycolysis flux (Ding et al., 2017). Interestingly, induction of aerobic glycolysis led to myofibroblast activation in vitro. Past research has illustrated that the metabolism of the renal medulla is primarily glycolysis, whereas aerobic oxidation of substrates and gluconeogenesis is prioritized in the renal cortex (Lee et al., 1962; Lee and Peterhm, 1969). This layer-dependent renal energy preference is explained by local tissue oxygen pressure. Moreover, in the outer medulla, where slightly less oxygen is available than in the cortex, glucose fuels the mitochondria (Eveloff et al., 1980), although succinate is prioritized as an energy source (Baverel et al., 1980). In the inner medulla, glycolysis plays a more critical role in metabolizing glucose to produce energy as oxygen consumption is lower (Baverel et al., 1980).

\section{Fatty Acid Transport and $\beta$-Oxidation}

Most fatty acids act as energy sources for peripheral tissues once they are released into the blood through the hydrolysis of triacylglycerols in adipose tissue. Circulating triacylglycerol is degraded by lipase to produce fatty acids and glycerin. Cytosolic fatty acids are converted to acyl-CoA by acyl-CoA synthetase, which cannot pass through the IMM of the mitochondria. First, the fatty acid portion of acyl-CoA is transferred to carnitine through carnitine acyltransferase to provide acylcarnitine. Then, acylcarnitine enters the mitochondrial matrix and reacts with Coenzyme $\mathrm{A}$ (CoA) and returns to acyl-CoA (Bremer, 1983; Brady et al., 1993). Acyl-CoA is then decomposed into two carbon units to produce acetyl-CoA in the stepwise sequence of oxidation, hydration, oxidation, and thiol cleavage. This process, known as $\beta$-oxidation, generates ubiquinol (QH2), NADH, GTP, and a sufficient amount of ATP (Raskind and El-Chaar, 2000).

As previously mentioned, glucose is a poor energy source for respiration in the kidney cortex, which contains glomeruli and proximal tubules. The preferred fuels are short- and longchain fatty acids and endogenous lipids, as well as ketone bodies, lactate, and some amino acids (Weidemann and Krebs, 1969; Klein et al., 1980). Conversely, chronic hyperinsulinemia enhances degradation of triglycerides in the adipocytes, thus elevating serum levels of non-esterified fatty acids. These elevated levels lead to the ectopic accumulation of lipids in organs outside of the lipid tissue, including the kidney. The excessive accumulation of lipids results in cellular damage, known as lipotoxicity (Weinberg, 2006; Ertunc and Hotamisligil, 2016; Nishi et al., 2019). For instance, fatty acids accumulated in the mitochondrial matrix are vulnerable to lipid peroxidation (Schrauwen and Hesselink, 2004; Schrauwen et al., 2010; Sergi et al., 2019), which can have lipotoxic effects on DNA, RNA, and proteins of the mitochondrial machinery, leading to organelle dysfunction. In AKI and diabetic nephropathy, $\beta$-oxidation in the mitochondria is decreased and the formation of lipid droplets inside the cell are increased, resulting in diminished ATP production (Simon and Hertig, 2015). Stimulation of proximal tubular culture cells with the fatty acid palmitate invokes the accumulation of abnormal organelles because of poor acidification of lysosomes (Yamamoto et al., 2017), even promoting lipoapoptosis (Katsoulieris et al., 2010).

\section{Electron Transfer System and Mitochondrial Reactive Oxygen Species}

The ETC is responsible for mitochondrial oxidative phosphorylation, which produces ATP using the oxygen-based fatty acids and pyruvate. In this process, five electrontransporting enzyme complexes (complexes I to $\mathrm{V}$ ) on the IMM, as well as the electron transporters ubiquinone and cytochrome $c$, excrete protons into the intermembrane space to drive ATP synthase. Although this process is efficient, insufficient reactions can produce reactive oxygen species (ROS). Oxidative stress reduces mitochondrial and cellular function and can even cause cell death by promoting lipid peroxidation in the IMM. This lipid peroxidation can change the membrane permeability and structure (Stewart and Heales, 2003) or disrupting calcium homeostasis, particularly affecting the oxidation state of specific thiol groups in proteins (Toescu, 2005). Mitochondria possess defense systems to scavenge ROS to protect them from excess radicals. For example, superoxide dismutase 2 (SOD2) transforms superoxide anions to oxygen and hydrogen peroxide (Weisiger and Fridovich, 1973). Also, coenzyme Q10 (CoQ10) can exist in two forms: Ubiquinone, an oxidized form, that acts as an electron carrier during mitochondrial respiration; and Ubiquinol, a reduced form, that is an endogenous antioxidant (Crane, 2001). Mutations in the genes that encode the CoQ10 pathway confer an inherited mitochondriopathy with primary renal involvement (Diomedi-Camassei et al., 2007).

In chronic hypoxic kidneys of rat, proteomic analysis identified maladaptive suppression of $\mathrm{Cu} / \mathrm{Zn}-\mathrm{SOD}$ enzymes as a mediator of a cycle of oxidative stress and subsequent renal injury (Son et al., 2008). Also, mice with cisplatininduced AKI treated with CoQ10 has less depletion of their antioxidant defense mechanisms (glutathione level and SOD activity), lipid peroxidation, and renal tissue damage (Fouad et al., 2010). The significance of mitochondrial ROS levels has also been implicated in diabetic kidney diseases (DKD). Mitochondrial superoxide and ATP production were increased in type 2 diabetic $d b / d b$ mice in the renal cortex, compared to control mice (Sourris et al., 2012); however, the excessive renal mitochondrial hydrogen peroxide production and membrane potential seen in $d b / d b$ mice were attenuated with CoQ10 treatment. This normalization of mitochondrial ROS generation caused by CoQ10 treatment decreases albuminuria (Sourris et al., 2012). NADPH oxidases (NOX) are the principal enzymes to generate nitrogen species and ROS, with NOX4 localized within the renal cortex and upregulated under hyperglycemic conditions within the mitochondria (Block et al., 2009). Intriguingly, pharmacological inhibition of NOX4 has potential for treatment of renal histopathology and albuminuria in $d b / d b$ mice (Sedeek et al., 2013). Also, chemical inactivation of NOX4 protected ApoE-deficient mice treated 
with streptozotocin from both structural and functional kidney damage (Jha et al., 2014).

\section{Electrochemical Gradient and Uncoupling}

The pumping of protons into the transmembrane space results in a difference of proton concentrations between the inside and outside the IMM (i.e., electrochemical gradient). These protons can return to the matrix through the ATP synthase pump, at which uses the potential to generate ATP from adenosine diphosphate (ADP) and inorganic phosphate (Pi). The generated ATP is then transported from the mitochondria to the cytoplasm by ATP/ADP transporters and becomes the active energy source for cells. Alternatively, proton in the mitochondrial intermembrane space released by the ETC may also return to the matrix by diffusing through the IMM without involvement in ATP synthesis. This flux is known as uncoupling, and the accumulated electrochemical potential is squandered as heat (Dlaskova et al., 2006). The transporter protein UCP uses this proton gradient between membranes to generate energy for oxidative phosphorylation (Ricquier et al., 1991).

The UCP has isoforms in mammals (UCP1-5). Thermogenin (UCP1) is present only in brown adipocytes, and contributes to heat production without movement during hibernation (Palou et al., 1998). Recently, UCP1 expression was reported in the ischemic kidneys (Jia et al., 2019) and speculated to protect the organ from hypoxia, since deletion of UCP1 worsened both ischemia or cisplatin induced AKI. Furthermore, peroxisome proliferator-activator receptor (PPAR) $\gamma$ agonist treatment increased UCP1 expression, suggesting their close relationship. Elsewhere, an early work combined immunohistochemistry and polymerase chain reaction techniques to unravel the UCP2 expression in rat kidneys, specifically the epithelial cells of the proximal tubules and the medullary thick ascending loop of Henle (Balaban and Mandel, 1980). Multiple reports suggest that tubular UCP2 expression is enhanced in kidneys that are diseased. Higher expression of UCP2 is found in diabetic kidneys (Balaban and Mandel, 1980). It was demonstrated that glutamate-stimulated oxygen consumption was increased in the isolated mitochondria from diabetic animals, and could be reduced by adding guanosine diphosphate, which inhibits UCP activity. These results imply that those mitochondria have increased uncoupling due to increased UCP2 protein expression (Friederich et al., 2008). In fibrotic kidneys, the expression of UCP2 in proximal tubular epithelial cells was increased (Jiang et al., 2013), and mice deficient in UCP2 were protected from kidney fibrosis induced by unilateral ureter obstruction (UUO). Intriguingly, UCP2 causes cultured epithelial cells to transdifferentiate and release cellular matrix. Regarding other UCP isoforms, UCP3 expression is found in the epithelial cells of the renal cell carcinoma (Braun et al., 2015). Intriguingly, their loss-of-function study indicates that UCP3 in carcinoma that originated from the proximal tubular cells helps resist against hypoxia/reoxygenation injury of cancer.

\section{Calcium Storage}

Intracellular calcium concentration is tightly regulated and plays a vital role in the signal transduction of cells. Although the ER stores the highest amount of intracellular calcium, mitochondria also have temporary capacity to store calcium, which contributes to the homeostasis of the overall intracellular calcium concentration (Brookes et al., 2004).

In kidney diseases, mitochondrial calcium uptake is impaired in tubular epithelia cells. Cation uptake in tubular cells is reduced per the cytoplasmic glutathione level in cisplatin-induced kidney damage (Kameyama and Gemba, 1991). Autosomal dominant polycystic kidney disease (ADPKD) is one of the most common monogenetic diseases, constituting approximately $5 \%$ of all kidney failure diseases (Levy and Feingold, 2000). Genes PKD1 (The European Polycystic Kidney Disease Consortium, 1994) and PKD2 (Mochizuki et al., 1996) encode polycystin 1 (PC1) and polycystin 2 (PC2), respectively, that are responsible for ADPKD; yet, the biological function of polycystins remains elusive and controversial (Douguet et al., 2019). Initial studies reported that PC1 and PC2 form a molecular complex configured as a calciumpermeable channel at the plasma membrane of renal tubular cells or neurons (Hanaoka et al., 2000; Delmas et al., 2004). Additionally, these PC1-PC2 complexes located in the primary cilium of kidney cells work as mechano-sensors to the intratubular shear stress (Nauli et al., 2003; AbouAlaiwi et al., 2009), but this mechanism has been challenged by subsequent data showing that stimulation of the primary cilium does not induce an increase in intraciliary calcium (Delling et al., 2016). Recently, researchers who focused on localization of the PC complex in MAMs discovered a novel role of these polycystins to regulate mitochondrial function (Padovano et al., 2017). PC1 interacts with the prolyl hydroxylase domain-containing protein (PHD3) to sense local oxygen pressure, and fluctuations in oxygen levels and the PHD3 activity modulate the subcellular localization and the calcium channel activity of the PC complex. PC1deficient tubular cells had reduced oxygen consumption rate in vitro, consistent with a reduction in the quantity of oxidative phosphorylation performed by these cells. Thus, deficiency in the PC1 protein may mimic a relatively low oxygen pressure and lead to mitochondrial dysfunction.

\section{Mitophagy: Mitochondrial Quality Control}

Malfunctioning and defective mitochondria are degraded through autophagy known as mitophagy. Impaired mitophagy causes the accumulation of abnormal organelles and severe mitochondrial dysfunction. The PTEN-induced kinase 1 (PINK1)-Parkin pathway is the most widely studied mechanism of mitophagy of neuron (Pickrell and Youle, 2015). Initially, both PINK1 and Parkin were known to be causative mutations in juvenile Parkinson's disease. For example, once mitochondria are damaged and have reduced membrane potential, PINK1 accumulates on the OMM, which recruits the E3 ubiquitin ligase, Parkin, for ubiquitination of PINK1. Then, light-chain-3 (LC3) receptors accumulate and invoke the autophagosome to degrade the dysfunctional mitochondria. In addition, BCL2 Interacting Protein 3 (BNIP3) and NIX in the OMM also regulate mitophagy (Zhang and Ney, 2009). In hypoxic cells, hypoxia-inducible factor-1 (HIF-1) is stabilized and promotes expression of the target genes that eradicates damaged mitochondria (Zhang and Ney, 2008). Furthermore, FUN14 Domain Containing 1 
(FUNDC1) in the OMM associates mitophagy with the LC3 receptor through its LC3-interacting region (LIR) domains under hypoxic conditions (Lv et al., 2017; Zhang et al., 2017). Under normal conditions, FUNDC1 is phosphorylated and this moiety blocks binding to LC3.

The pathogenic role of mitophagy in kidney disease still requires further investigation (Bhatia and Choi, 2019; Wang et al., 2020). Tissue damage induced by renal ischemia is prolonged in mice deficient in PINK1, PARK2, or both, representing severe mitochondrial damage and higher ROS production (Tang et al., 2018). The PINK1-Parkin pathway expression is increased in tubular cells stimulated with cisplatin. Interestingly, the silencing of PINK1 or Parkin attenuates mitophagy and promotes cell apoptosis as visualized with immunofluorescence microscopy (Zhao et al., 2017). The protective effect of PINK1/PARK2dependent mitophagy can also be demonstrated in AKI induced by contrast media (Yang et al., 2018). The BNIP3 expression in cultured renal tubular cells is enhanced by oxygenglucose deprivation/reperfusion. Finally, BNIP3-deficient mice demonstrate worsened renal ischemic injury due to impaired mitophagy (Tang et al., 2019). These findings suggest that the proper coordination of mitophagy is critical for protection against acute nephrotoxicity, and chronic renal fibrosis is also regulated by the PINK1-Parkin pathway in macrophages (Bhatia et al., 2019).

\section{Apoptosis}

Apoptosis is an active and molecular programmed cell death that requires energy to occur. Oxidant stress, abundant cytokines, or hypoxia deteriorate the mitochondrial membrane potential by excreting ROS and cytochrome $\mathrm{c}$ from the mitochondria to trigger apoptosis through the p53 and Bcl-2 family proteins (Susnow et al., 2009; Redza-Dutordoir and Averill-Bates, 2016). Cytochrome $\mathrm{c}$ binds to the cytoplasmic caspase- 9 and forms an aggregate that activates the caspase- 9 and inducing apoptosis (Bratton and Salvesen, 2010).

In a damaged kidney, epithelial cells (Shimizu and Yamanaka, 1993) and partially podocytes (Shankland, 2006) are the principal cell types that undergo cell death. The signaling pathway underlying kidney cell apoptosis is not always p53-mediated. Cisplatin can induce Bax-mediated apoptosis in primarycultured tubular cells isolated from mice deficient in p53 (Jiang et al., 2009), suggesting only a partial effect of p53 inhibition on cisplatin nephrotoxicity. Conversely, apoptosis of the renal cells may also be beneficial during the recovery phase, and assist in fine-tuning the number of renal cells created by balancing an exaggerated proliferative response.

\section{MITOCHONDRIA AND SARCOPENIA IN CKD}

\section{Uremic Sarcopenia}

Sarcopenia is the progressive reduction of muscle weight and strength, leading to poor physical activity and quality of life, and even increasing the risk of death. Age-related muscle loss and dysfunction were initially defined as sarcopenia, whereas degradation from a chronic inflammatory or malnutritional illness is classified as secondary sarcopenia. CKD is a chronic illness that exhibits sarcopenia symptoms (Moorthi and Avin, 2017). The muscle mass is reduced in those with a greater amount of albuminuria or a lower glomerular filtration rate (GFR) (Foley et al., 2007). Importantly, CKD patients with sarcopenia show higher rates of mortality and longer hospital stays (Sinkeler et al., 2013; Pereira et al., 2015). Epidemiological evidence suggests that multiple lifestyle and clinical factors contribute to the progression of sarcopenia in $\mathrm{CKD}$, including malnutrition, reduced protein intake, insufficient or deficient exercise, chronic inflammation, metabolic acidosis, atherosclerosis, and a lack of natural vitamin D (Stenvinkel and Alvestrand, 2002; Delano and Moldawer, 2006).

\section{Mitochondrial Dysfunction in Skeletal Muscles With Uremia}

Several experiments indicate mitochondrial dysfunction in the skeletal muscle of patients with CKD (Gamboa et al., 2016; Sato et al., 2016; Kikuchi et al., 2019; Thome et al., 2019; Xu et al., 2020). Both mitochondrial volume density and mtDNA copy numbers were decreased in skeletal biopsy specimens sampled from kidney failure patients who underwent HD (Gamboa et al., 2016) or PD (Xu et al., 2020) (Figures 1B, 2). A recent human study assessed the phosphocreatine recovery time constant to measure mitochondrial function in the knee extensors using with ${ }^{31} \mathrm{P}$ magnetic resonance spectroscopy (Gamboa et al., 2020). This study demonstrated that the phosphocreatine recovery was extended in pre-dialysis $\mathrm{CKD}$ as well as $\mathrm{HD}$ patients, compared to healthy control participants (Gamboa et al., 2020). The mitochondrial dysfunction in human skeletal muscle was also associated with poor physical activity performance when evaluated with a 6-min walk test. This result indicates that uremic sarcopenia is already progressing even before CKD advances (Nishi et al., 2020; Ryan, 2020).

Several studies have recognized the impaired role of the PDHC at a molecular level in the mitochondria of skeletal muscle in CKD sarcopenia (Sato et al., 2016; Thome et al., 2019; $\mathrm{Xu}$ et al., 2020). The PDHC is essential to energy production under anaerobic condition, as the enzyme converts pyruvate to acetyl-CoA for the TCA cycle. Insufficient activation of PDHC prevents TCA cycle metabolism and reduces ATP production in the mitochondria, resulting in an energy shortage in the skeletal muscle. The activity of the PDHC is regulated by the expression of several kinases and phosphatase via reversible phosphorylation. Inhibition occurs when phosphorylated at Ser232, Ser293, and Ser300 of the PDH E1- $\alpha$ subunit by the PDH kinases PDK-1, PDK-2, PDK-3, and PDK-4, and re-activated by dephosphorylation by the two PDH phosphatases PDP1 and PDP2. In murine $\mathrm{C} 2 \mathrm{C} 12$ myocytes, cell cultures exposed to a uremic toxin promote glycolysis with excess antioxidative responses, leading to mitochondrial TCA cycle down-regulation and ATP shortage (Sato et al., 2016). Moreover, PDHC activity and phospho-PDH (S293) are decreased in the skeletal muscle of patients with advanced CKD, whereas PDK4 protein levels are upregulated (Xu et al., 2020). Treatment of CKD in mice 




FIGURE 2 | Mitochondrial dysfunction in the kidney and the skeletal muscle. Both kidney failure and sarcopenia are associated with mitochondrial damage, and there are several common findings or processes in the kidney and the skeletal muscle. Mitochondrial damage, usually accompanied with morphological change for altered dynamics and decreased biogenesis, results in ROS accumulation or deficiency in ATP production. ROS production, which can induce mitochondrial damage, promote inflammation or cytochrome $\mathrm{C}$ release leading to apoptosis. Low efficiency in ATP production also leads to cell injury. CKD progression or uremic sarcopenia can result from combination of these phenomena. Therapeutics for CKD have various effects on some or all of these processes. At the same time, these processes can still be a novel therapeutic target. CKD, chronic kidney disease; ROS, reactive oxygen species; ATP, adenosine triphosphate.

with dichloroacetate to activate PDHC improved the treadmill running test distance (Tamaki et al., 2014). The uremic condition does not impair the overall activity of mitochondrial enzymes. Isolated mitochondria from murine skeletal muscle had impaired malate and glutamate dehydrogenases, as well as ETC complexes III and IV, by several uremic metabolites (Thome et al., 2019). Treatment with 5-aminolevulinic acid to transport electrons in the mitochondrial ETC also increases the skeletal muscle weight and the mitochondrial amount, thereby improving physical activity (Fujii et al., 2017). Altogether, the reinforcement of muscle mitochondria function serves a potential strategy for eradicating uremic sarcopenia.

\section{DRUGS}

Almost no treatments have been approved for slowing or reversing CKD progression, although various treatments for CKD and its complications are currently being trialed. These treatment approaches may potentially have beneficial effects, such as relieving renal fibrosis (a hallmark of CKD) and minimizing AKI in patients, who are predisposed to the development and progression of $\mathrm{CKD}$. This chapter discusses the various therapeutic agents and potentially protective agents for CKD with a focus on the pharmacological effects on the mitochondria in the kidney or skeletal muscle.

\section{Erythropoietin}

Erythropoietin (EPO) analogs are a major therapeutic approach to treating anemia from EPO deficiency in CKD. Erythropoietin replenishment has been reported to slow CKD progression (Gouva et al., 2004), as EPO may provide renoprotection from some factors related to the mitochondria. Erythropoietin ameliorates lipopolysaccharide-induced AKI (Stoyanoff et al., 2014). Renoprotection is promoted via an anti-apoptotic effect from the expression of the EPO receptor, the reduction of the $\mathrm{Bax} / \mathrm{Bcl}-\mathrm{XL}$ ratio, the inhibition of cytochrome-c release into the cytosol, and the decrease of active caspase-3 expression. EPO treatment also reduces renal fibrosis in UUO model rats, and downregulates Drp1 overexpression to reduce mitochondria fission (Zhao et al., 2015).

Patients with CKD develop impaired mitochondrial energetics associated with the disease severity in skeletal muscle (Kestenbaum et al., 2020). CKD mice with muscle atrophy have decreased mitochondrial activity and amount, metabolism related to AMP-activated protein kinase (AMPK) phosphorylation and Pgcla gene expression (Tamaki et al., 2014). The EPO receptor expression can be seen in skeletal 
muscle (Lamon and Russell, 2013), and EPO treatment increases the PGC- $1 \alpha$ protein and gene expression in combination with exercise (Pin et al., 2015). Elevated EPO signaling leads to the activation of mitochondrial biogenesis and metabolism as indicated by increased AMPK phosphorylation, PGC1 $\alpha$ expression, and oxygen consumption rate in both in vitro and in vivo models (Wang et al., 2013). Thus, EPO treatment may alleviate mitochondrial dysfunction in skeletal muscle in CKD and improve muscle amount and performance.

\section{HIF-PH Inhibitor}

Hypoxia-inducible factor prolyl hydroxylase (HIF-PH) inhibitors are another emerging therapeutics for renal anemia, as these inhibitors have already been effective in treating patients with or without dialysis (Chen et al., 2019a,b). HIF-PHs stimulates EPO production in the kidney via the activation of the HIF pathway. The agents exert non-hematopoietic effects, as HIF up-regulates the transcription of more than 100 genes involved in hypoxic adaptation. Moreover, HIF- $1 \alpha$ regulates cellular metabolism against oxidative phosphorylation via LDHA, PDK, and COX4-2 upregulation and encourages mitochondrial autophagy through BNIP upregulation, resulting in the optimized efficiency of mitochondrial respiration and ROS production (Semenza et al., 1996; Kim et al., 2006; Papandreou et al., 2006; Fukuda et al., 2007; Zhang et al., 2008; Bellot et al., 2009). Moreover, HIF-1 $\alpha$ is crucial in preventing mitochondrial dysfunction and apoptosis under hypoxic conditions. Cobalt chloride salt is a classical HIF$\mathrm{PH}$ inhibitor that protects against cisplatin-induced kidney injury in mice (Tanaka et al., 2005). The emerging HIF-PH inhibitor enarodustat also suppresses mitochondrial respiration in HK-2 tubular cells and changes energy metabolism in early DKD mice (Hasegawa et al., 2020).

HIF-1 $\alpha$ plays a part in regulation of skeletal muscle function, since a skeletal muscle-specific HIF- $1 \alpha$ knockouts in mice have increased mitochondrial activity with higher citrate synthase activity and oxidative metabolism as well as slight increases in the mitochondrial amount and endurance capacity (Mason et al., 2004). Moreover, PHD1 is also associated with mitochondrial changes in skeletal muscle (Aragones et al., 2008). The silencing of PHD1 in myofiber cells decreases oxidative metabolism and less mitochondrial ultrastructural changes compared to ischemiaexhibiting control myofibers with swollen mitochondria, inner lucency, and fractured cristae (Aragones et al., 2008). HIF-PH inhibitors have also been reported to reduce the levels of ROS with glycolytic metabolic shift and increase cell viability in renal proximal tubule cells (Ito et al., 2020) and neuronal cells with glutamate-induced oxytosis (Neitemeier et al., 2016). HIF-PH inhibitor MK-8617 ameliorates myopathy in 5/6 nephrectomy CKD mice and corrects abnormalities in the mitochondrial number and size in skeletal muscle (Qian et al., 2019). Future HIF-PH inhibitors as novel HIF stabilizers may relieve uremic sarcopenia, but they require further investigation.

\section{Nrf2 Activator}

The progression of CKD leads to oxidative stress and impaired antioxidant capacity that are associated with the impairment of Nrf2 activity (Ruiz et al., 2013). Bardoxolone methyl, an
Nrf2-activating triterpenoid, has been reported to improve renal function in DKD in humans (de Zeeuw et al., 2013), although this drug is not yet approved for patient use. Bardoxolone methyl improved the estimated GFR (eGFR) above baseline in $\mathrm{CKD} /$ type 2 diabetes patients in a BEAM randomized, placebocontrolled, 52 week trial (Pergola et al., 2011); however, this trial was prematurely terminated due to as a result of an increased rate of cardiovascular events leading to hospitalization or death in the treatment group because of heart failure (de Zeeuw et al., 2013). Thereafter, the efficacy on DKD was evaluated in a TSUBAKI clinical study in Japan that payed careful attention to cardiac events by excluding patients with risk factors for volume overload or prior history of heart failure (Nangaku et al., 2020). Nrf2 activation also relieves renal injury in non-DKD model mice, and the Nrf2-activating triterpenoid CDDO-imidazolide seems to protect the kidney from ischemia-reperfusion injury by decreasing ROS production in mice (Liu et al., 2014). Another Nrf2 activator, dihydroCDDO-trifluoroethyl amide (dh404), alleviates proteinuriainduced tubular damage by stopping mitochondrial structural changes, such as decreasing size, number, and breakdown of the cristae structure of mitochondria in vivo (Nagasu et al., 2019). Moreover, activator dh404 also decreased mitochondrial ROS and the preservation of mitochondrial membrane potential in vitro (Nagasu et al., 2019).

$\mathrm{Nrf} 2$ is important for maintaining mitochondrial function, muscle mitohormesis, and oxidative stress defense in skeletal muscle (Coleman et al., 2018; Kitaoka et al., 2019). Moreover, Nrf2 is involved in uremic sarcopenia, which has reduced skeletal muscle mitochondrial mass and gene expression related to mitochondrial biogenesis, including Nrf2 (Liu et al., 2019; Watson et al., 2020). Genetic Nrf2 activation in skeletal muscle improves endurance capacity and increased oxygen consumption without altering mtDNA content (Uruno et al., 2016). Treatment with Nrf2-activating compounds also increases running endurance in rodents (Uruno et al., 2016). Altogether, these results indicate that Nrf2 activators could be effective therapeutic against sarcopenia in $\mathrm{CKD}$ patients and require further investigation.

\section{SGLT2 Inhibitor}

Recent research has focused on sodium-glucose transporter 2 (SGLT2) inhibitors as a beneficial treatment for DKD. The CREDENCE trial assessed the effects of inhibitor canagliflozin on renal conditions in patients with type 2 diabetes and albuminuric CKD (Perkovic et al., 2019). Canagliflozin had favorable results with a $30 \%$ risk reduction in the composite outcome of kidney failure (dialysis, transplantation, or a sustained estimated GFR of $<15 \mathrm{ml}$ per minute per $1.73 \mathrm{~m}^{2}$ ), a doubling of the serum creatinine level, or death from renal or cardiovascular causes, thereby resulting in early cessation of the trial (Perkovic et al., 2019). Similarly, early cessation of the DAPA-CKD trial was also announced by AstraZeneka (Heerspink et al., 2020), whereas their EMPA-KIDNEY trial is still under way ${ }^{1}$. There are various mechanisms of renoprotection exhibited

\footnotetext{
${ }^{1}$ www.empakidney.org; accessed April 24, 2020
} 
by the SGLT2 inhibitors, including a decrease in blood glucose levels, tubuloglomerular feedback, upregulation of HIF and EPO, and subsequent hematocrit elevation and oxygen supply (Vallon and Thomson, 2020). The inhibitor ipragliflozin protects tubular cells in the high-fat diet-fed mice (Takagi et al., 2018). These mice show no longer abnormal mitochondrial fission associated with increased oxidative stress, lower gene expression of Opa1 and Mfn2, and higher expression of Drp1 (Takagi et al., 2018). Ipragliflozin also reduces ROS and mitochondrial dysfunction in tubular epithelial cells and glomerular podocytes in diabetic $d b / d b$ mice (Kamezaki et al., 2018).

SGLT2 inhibitors have also been reported to have protective effects against muscle atrophy and lowered exercise performance (Hirata et al., 2019). Empaglifrozin improves symptoms for diabetic sarcopenia in hyperglycemic Akita mice, though it is unclear whether there are other factors beyond the antidiabetic effects and improving muscle mass (Hirata et al., 2019). Empagliflozin also restores lowered exercise capacity in a murine heart failure model (Nambu et al., 2020). The drug increases endurance capacity, but not muscle weight or muscle strength, by restoring mitochondrial fatty acid oxidation in skeletal muscle (Nambu et al., 2020).

\section{AST-120}

AST-120 is an agent that inhibits the accumulation of uremic toxins and is often prescribed to CKD patients to slow the progression of renal failure. The efficacy of AST-120 to slow down CKD progression is controversial, as various clinical trials have failed to show renoprotective effects (Schulman et al., 2015; Cha et al., 2016); however, the drug remains a standard method of treatment for CKD patients.

AST-120 may have beneficial effects on muscles since uremic toxins are harmful to them. AST-120 may improve mitochondrial status by reducing the accumulation of indoxyl sulfate, which induces mitochondrial dysfunction and ATP shortage in muscle cells (Sato et al., 2016). As for in vivo models, AST-120 administration improves running endurance reduced in subtotal nephrectomy mice, and attenuates harmful changes, such as down-regulated citrate synthase activity, decreased expression of mitochondrial biogenesis genes like $P g c l \alpha$, and increased superoxide production (Nishikawa et al., 2015). There are no significant reports on the clinical usage of AST-120 against uremic sarcopenia, so further studies are required to indicate clinical efficacy.

\section{Carnitine}

Patients with pre-dialysis CKD have higher plasma L-carnitine levels than healthy individuals (Rodriguez-Segade et al., 1986;

\section{REFERENCES}

AbouAlaiwi, W. A., Takahashi, M., Mell, B. R., Jones, T. J., Ratnam, S., Kolb, R. J., et al. (2009). Ciliary polycystin-2 is a mechanosensitive calcium channel involved in nitric oxide signaling cascades. Circ. Res. 104, 860-869. doi: 10.1161/circresaha.108.192765
Guarnieri et al., 1987). Nevertheless, hemodialysis patients show low plasma and muscle L-carnitine levels that correlate with the dialysis vintage (Sakurauchi et al., 1998; Debska et al., 2000; Evans, 2003).

Carnitine deficiency is associated with EPO-resistant anemia, intradialytic hypotension, cardiomyopathy, and skeletal muscle dysfunction (Karpati et al., 1975). Therefore, L-carnitine supplementation is recommended to relieve such problems (Eknoyan et al., 2003). There is no firm conclusion regarding the clinical efficacy of L-carnitine on skeletal muscle (Hurot et al., 2002), although some trials have shown improvement in muscle volume, strength, and maximal oxygen consumption (Ahmad et al., 1990; Siami et al., 1991). In animal models, L-carnitine improved endurance capacity lowered in CKD mice, normalized PGC- $1 \alpha$ expression, and reduced a blunt reduction in type I muscle fibers seen in untreated controls (Enoki et al., 2017).

\section{FUTURE DIRECTIONS}

Although mitochondrial dysfunction has been involved in various pathologies, including $\mathrm{CKD}$ and sarcopenia, clinical impact of this organelle dysfunction in patients with CKD has not been fully explored. This article reviewed essential mitochondrial functions, mitochondrial changes in CKD and sarcopenia conditions, and the effects of emerging therapeutics on the kidney and skeletal muscle. A comprehensive understanding of mitochondrial physiology is critical for understanding the pathogenesis of kidney diseases and muscle wasting. Furthermore, therapeutic strategies against mitochondrial dysfunctions could lead to drastic progress in the treatment and regression of CKD or sarcopenia.

\section{AUTHOR CONTRIBUTIONS}

KT wrote the original manuscript. $\mathrm{HN}$ and $\mathrm{RI}$ revised the manuscript. All authors contributed to the article and approved the submitted version.

\section{FUNDING}

This work was supported by the Japan Society for the Promotion of Science Grants-in-Aid for Scientific Research 18K08232 (to $\mathrm{HN}$ ) and 15KT0088, 16K15465, and $18 \mathrm{H} 02727$ (to RI); and Kyowa Kirin Co. Ltd. (to RI). The funder Kyowa Kirin Co. Ltd. was not involved in the study design, collection, analysis, interpretation of data, the writing of this article or the decision to submit it for publication.

Ahmad, S., Robertson, H. T., Golper, T. A., Wolfson, M., Kurtin, P., Katz, L. A., et al. (1990). Multicenter trial of L-carnitine in maintenance hemodialysis patients. II. Clinical and biochemical effects. Kidney Int. 38, 912-918. doi: 10.1038/ki. 1990.290

Allan, V. J., and Schroer, T. A. (1999). Membrane motors. Curr. Opin. Cell Biol. $11,476-482$. 
Appenzeller-Herzog, C., and Simmen, T. (2016). ER-luminal thiol/selenolmediated regulation of Ca2+ signalling. Biochem. Soc. Trans. 44, 452-459. doi: $10.1042 / \mathrm{bst} 20150233$

Aragones, J., Schneider, M., Van Geyte, K., Fraisl, P., Dresselaers, T., Mazzone, M., et al. (2008). Deficiency or inhibition of oxygen sensor Phd1 induces hypoxia tolerance by reprogramming basal metabolism. Nat. Genet. 40, 170-180. doi: 10.1038/ng.2007.62

Ayanga, B. A., Badal, S. S., Wang, Y., Galvan, D. L., Chang, B. H., Schumacker, P. T., et al. (2016). Dynamin-Related protein 1 deficiency improves mitochondrial fitness and protects against progression of diabetic nephropathy. J. Am. Soc. Nephrol. 27, 2733-2747. doi: 10.1681/asn.2015101096

Balaban, R. S., and Mandel, L. J. (1980). Coupling of aerobic metabolism to active ion transport in the kidney. J. Physiol. 304, 331-348. doi: 10.1113/jphysiol.1980. sp013327

Baverel, G., Forissier, M., and Pellet, M. (1980). Lactate and pyruvate metabolism in dog renal outer medulla. Effects of oleate and ketone bodies. Int. J. Biochem. 12, 163-168. doi: 10.1016/b978-0-08-025517-0.50037-0

Bellot, G., Garcia-Medina, R., Gounon, P., Chiche, J., Roux, D., Pouyssegur, J., et al. (2009). Hypoxia-induced autophagy is mediated through hypoxia-inducible factor induction of BNIP3 and BNIP3L via their BH3 domains. Mol. Cell. Biol. 29, 2570-2581. doi: 10.1128/mcb.00166-09

Benner, C., Konovalov, S., Mackintosh, C., Hutt, K. R., Stunnenberg, R., and GarciaBassets, I. (2013). Decoding a signature-based model of transcription cofactor recruitment dictated by cardinal cis-regulatory elements in proximal promoter regions. PLoS Genet. 9:e1003906. doi: 10.1371/journal.pgen.1003906

Bhatia, D., and Choi, M. E. (2019). The emerging role of mitophagy in kidney diseases. J. Life Sci. 1, 13-22. doi: 10.36069/jols/20191203

Bhatia, D., Chung, K. P., Nakahira, K., Patino, E., Rice, M. C., Torres, L. K., et al. (2019). Mitophagy-dependent macrophage reprogramming protects against kidney fibrosis. JCI Insight 4:e132826.

Block, K., Gorin, Y., and Abboud, H. E. (2009). Subcellular localization of Nox4 and regulation in diabetes. Proc. Natl. Acad. Sci. U.S.A. 106, 14385-14390. doi: 10.1073/pnas.0906805106

Bonifacino, J. S., and Glick, B. S. (2004). The mechanisms of vesicle budding and fusion. Cell 116, 153-166. doi: 10.1016/s0092-8674(03)01079-1

Brady, P. S., Ramsay, R. R., and Brady, L. J. (1993). Regulation of the long-chain carnitine acyltransferases. FASEB J. 7, 1039-1044. doi: 10.1096/fasebj.7.11. 8370473

Bratton, S. B., and Salvesen, G. S. (2010). Regulation of the Apaf-1-caspase9 apoptosome. J. Cell Sci. 123(Pt 19), 3209-3214. doi: 10.1242/jcs. 073643

Braun, N., Klumpp, D., Hennenlotter, J., Bedke, J., Duranton, C., Bleif, M., et al. (2015). UCP-3 uncoupling protein confers hypoxia resistance to renal epithelial cells and is upregulated in renal cell carcinoma. Sci. Rep. 5:13450.

Bremer, J. (1983). Carnitine-metabolism and functions. Physiol. Rev. 63, 14201480.

Brookes, P. S., Yoon, Y., Robotham, J. L., Anders, M. W., and Sheu, S. S. (2004). Calcium, ATP, and ROS: a mitochondrial love-hate triangle. Am. J. Physiol. Cell Physiol. 287, C817-C833.

Brooks, C., Wei, Q., Cho, S. G., and Dong, Z. (2009). Regulation of mitochondrial dynamics in acute kidney injury in cell culture and rodent models. J. Clin. Invest. 119, 1275-1285. doi: 10.1172/jci37829

Cha, R. H., Kang, S. W., Park, C. W., Cha, D. R., Na, K. Y., Kim, S. G., et al. (2016). A Randomized, Controlled Trial of Oral Intestinal Sorbent AST-120 on Renal Function Deterioration in Patients with Advanced Renal Dysfunction. Clin. J. Am. Soc. Nephrol. 11, 559-567. doi: 10.2215/cjn.12011214

Chen, N., Hao, C., Liu, B. C., Lin, H., Wang, C., Xing, C., et al. (2019a). Roxadustat treatment for anemia in patients undergoing long-term dialysis. N. Engl. J. Med. 381, 1011-1022. doi: 10.1056/nejmoa1901713

Chen, N., Hao, C., Peng, X., Lin, H., Yin, A., Hao, L., et al. (2019b). Roxadustat for anemia in patients with kidney disease not receiving dialysis. N. Engl. J. Med. 381, 1001-1010.

Chen, Q., Sun, L., and Chen, Z. J. (2016). Regulation and function of the cGASSTING pathway of cytosolic DNA sensing. Nat. Immunol. 17, 1142-1149. doi: 10.1038/ni.3558

Coleman, V., Sa-Nguanmoo, P., Koenig, J., Schulz, T. J., Grune, T., Klaus, S., et al. (2018). Partial involvement of Nrf2 in skeletal muscle mitohormesis as an adaptive response to mitochondrial uncoupling. Sci. Rep. 8:2446.
Crane, F. L. (2001). Biochemical functions of coenzyme Q10. J. Am. Coll. Nutr. 20, 591-598. doi: 10.1080/07315724.2001.10719063

de Brito, O. M., and Scorrano, L. (2008). Mitofusin 2 tethers endoplasmic reticulum to mitochondria. Nature 456, 605-610. doi: 10.1038/nature07534

de Zeeuw, D., Akizawa, T., Audhya, P., Bakris, G. L., Chin, M., Christ-Schmidt, H., et al. (2013). Bardoxolone methyl in type 2 diabetes and stage 4 chronic kidney disease. N. Engl. J. Med. 369, 2492-2503.

Debska, S., Kawecka, A., Wojnarowski, K., Prajs, J., Malgorzewicz, S., Kunicka, D., et al. (2000). Correlation between plasma carnitine, muscle carnitine and glycogen levels in maintenance hemodialysis patients. Int. J. Artif. Organs. 23, 90-96. doi: $10.1177 / 039139880002300205$

Delano, M. J., and Moldawer, L. L. (2006). The origins of cachexia in acute and chronic inflammatory diseases. Nutr. Clin. Pract. 21, 68-81. doi: 10.1177/ 011542650602100168

Delling, M., Indzhykulian, A. A., Liu, X., Li, Y., Xie, T., Corey, D. P., et al. (2016). Primary cilia are not calcium-responsive mechanosensors. Nature 531, 656-660. doi: 10.1038/nature17426

Delmas, P., Nauli, S. M., Li, X., Coste, B., Osorio, N., Crest, M., et al. (2004). Gating of the polycystin ion channel signaling complex in neurons and kidney cells. FASEB J. 18, 740-742. doi: 10.1096/fj.03-0319fje

Ding, H., Jiang, L., Xu, J., Bai, F., Zhou, Y., Yuan, Q., et al. (2017). Inhibiting aerobic glycolysis suppresses renal interstitial fibroblast activation and renal fibrosis. Am. J. Physiol. Renal Physiol. 313, F561-F575.

Diomedi-Camassei, F., Di Giandomenico, S., Santorelli, F. M., Caridi, G., Piemonte, F., Montini, G., et al. (2007). COQ2 nephropathy: a newly described inherited mitochondriopathy with primary renal involvement. J. Am. Soc. Nephrol. 18, 2773-2780. doi: 10.1681/asn.2006080833

Dlaskova, A., Spacek, T., Skobisova, E., Santorova, J., and Jezek, P. (2006). Certain aspects of uncoupling due to mitochondrial uncoupling proteins in vitro and in vivo. Biochim. Biophys. Acta 1757, 467-473. doi: 10.1016/j.bbabio.2006. 05.005

Douguet, D., Patel, A., and Honore, E. (2019). Structure and function of polycystins: insights into polycystic kidney disease. Nat. Rev. Nephrol. 15, 412-422. doi: 10.1038/s41581-019-0143-6

Eknoyan, G., Latos, D. L., and Lindberg, J. (2003). National Kidney Foundation Carnitine Consensus C. Practice recommendations for the use of L-carnitine in dialysis-related carnitine disorder. National Kidney Foundation Carnitine Consensus Conference. Am. J. Kidney Dis. 41, 868-876. doi: 10.1016/s02726386(03)00110-0

Enoki, Y., Watanabe, H., Arake, R., Fujimura, R., Ishiodori, K., Imafuku, T., et al. (2017). Potential therapeutic interventions for chronic kidney disease-associated sarcopenia via indoxyl sulfate-induced mitochondrial dysfunction. J. Cachexia Sarcopenia Muscle 8, 735-747. doi: 10.1002/jcsm. 12202

Ertunc, M. E., and Hotamisligil, G. S. (2016). Lipid signaling and lipotoxicity in metaflammation: indications for metabolic disease pathogenesis and treatment. J. Lipid Res. 57, 2099-2114. doi: 10.1194/jlr.r066514

Evans, A. (2003). Dialysis-related carnitine disorder and levocarnitine pharmacology. Am. J. Kidney Dis. 41(4 Suppl. 4), S13-S26.

Eveloff, J., Haase, W., and Kinne, R. (1980). Separation of renal medullary cells: isolation of cells from the thick ascending limb of Henle's loop. J. Cell Biol. 87(3 Pt 1), 672-681. doi: 10.1083/jcb.87.3.672

Foley, R. N., Wang, C., Ishani, A., Collins, A. J., and Murray, A. M. (2007). Kidney function and sarcopenia in the United States general population: NHANES III. Am. J. Nephrol. 27, 279-286. doi: 10.1159/000101827

Fouad, A. A., Al-Sultan, A. I., Refaie, S. M., and Yacoubi, M. T. (2010). Coenzyme Q10 treatment ameliorates acute cisplatin nephrotoxicity in mice. Toxicology 274, 49-56. doi: 10.1016/j.tox.2010.05.007

Friederich, M., Fasching, A., Hansell, P., Nordquist, L., and Palm, F. (2008). Diabetes-induced up-regulation of uncoupling protein-2 results in increased mitochondrial uncoupling in kidney proximal tubular cells. Biochim. Biophys. Acta 1777, 935-940. doi: 10.1016/j.bbabio.2008.03.030

Fujii, C., Miyashita, K., Mitsuishi, M., Sato, M., Fujii, K., Inoue, H., et al. (2017). Treatment of sarcopenia and glucose intolerance through mitochondrial activation by 5-aminolevulinic acid. Sci. Rep. 7:4013.

Fujimoto, M., and Hayashi, T. (2011). New insights into the role of mitochondriaassociated endoplasmic reticulum membrane. Int. Rev. Cell Mol. Biol. 292, 73-117. doi: 10.1016/b978-0-12-386033-0.00002-5 
Fukuda, R., Zhang, H., Kim, J. W., Shimoda, L., Dang, C. V., and Semenza, G. L. (2007). HIF-1 regulates cytochrome oxidase subunits to optimize efficiency of respiration in hypoxic cells. Cell 129, 111-122. doi: 10.1016/j.cell.2007. 01.047

Gamboa, J. L., Billings, F. T., Bojanowski, M. T., Gilliam, L. A., Yu, C., Roshanravan, B., et al. (2016). Mitochondrial dysfunction and oxidative stress in patients with chronic kidney disease. Physiol. Rep. 4:e12780.

Gamboa, J. L., Roshanravan, B., Towse, T., Keller, C. A., Falck, A. M., Yu, C., et al. (2020). Skeletal muscle mitochondrial dysfunction is present in patients with CKD before Initiation of Maintenance Hemodialysis. Clin. J. Am. Soc. Nephrol. 15, 926-936. doi: 10.2215/cjn.10320819

Gouva, C., Nikolopoulos, P., Ioannidis, J. P., and Siamopoulos, K. C. (2004). Treating anemia early in renal failure patients slows the decline of renal function: a randomized controlled trial. Kidney Int. 66, 753-760. doi: 10.1111/ j.1523-1755.2004.00797.x

Gray, L. R., Tompkins, S. C., and Taylor, E. B. (2014). Regulation of pyruvate metabolism and human disease. Cell. Mol. Life Sci. 71, 2577-2604. doi: 10.1007/ s00018-013-1539-2

Graziewicz, M. A., Longley, M. J., and Copeland, W. C. (2006). DNA polymerase gamma in mitochondrial DNA replication and repair. Chem. Rev. 106, 383-405. doi: $10.1021 / \mathrm{cr} 040463 \mathrm{~d}$

Guarnieri, G., Toigo, G., Crapesi, L., Situlin, R., Del Bianco, M. A., Corsi, M., et al. (1987). Carnitine metabolism in chronic renal failure. Kidney Int. 22, S116-S127.

Gureev, A. P., Shaforostova, E. A., and Popov, V. N. (2019). Regulation of mitochondrial biogenesis as a way for active longevity: interaction between the Nrf2 and PGC-1alpha signaling pathways. Front. Genet. 10:435. doi: 10.3389/ fgene.2019.00435

Hanaoka, K., Qian, F., Boletta, A., Bhunia, A. K., Piontek, K., Tsiokas, L., et al. (2000). Co-assembly of polycystin-1 and -2 produces unique cation-permeable currents. Nature 408, 990-994. doi: 10.1038/35050128

Hasegawa, S., Tanaka, T., Saito, T., Fukui, K., Wakashima, T., Susaki, E. A., et al. (2020). The oral hypoxia-inducible factor prolyl hydroxylase inhibitor enarodustat counteracts alterations in renal energy metabolism in the early stages of diabetic kidney disease. Kidney Int. 97, 934-950. doi: 10.1016/j.kint. 2019.12.007

Hayashi, T., and Su, T. P. (2007). Sigma-1 receptor chaperones at the ERmitochondrion interface regulate $\mathrm{Ca}(2+)$ signaling and cell survival. Cell 131, 596-610. doi: 10.1016/j.cell.2007.08.036

Heerspink, H. J. L., Stefansson, B. V., Chertow, G. M., Correa-Rotter, R., Greene, T., Hou, F. F., et al. (2020). Rationale and protocol of the Dapagliflozin And Prevention of Adverse outcomes in Chronic Kidney Disease (DAPA-CKD) randomized controlled trial. Nephrol. Dial. Transplant. 35, 274-282.

Hirata, Y., Nomura, K., Senga, Y., Okada, Y., Kobayashi, K., Okamoto, S., et al. (2019). Hyperglycemia induces skeletal muscle atrophy via a WWP1/KLF15 axis. JCI Insight 4:e124952.

Hurot, J. M., Cucherat, M., Haugh, M., and Fouque, D. (2002). Effects of L-carnitine supplementation in maintenance hemodialysis patients: a systematic review. J. Am. Soc. Nephrol. 13, 708-714.

Inoue, T., Maekawa, H., and Inagi, R. (2019). Organelle crosstalk in the kidney. Kidney Int. 95, 1318-1325. doi: 10.1016/j.kint.2018.11.035

Ishimoto, Y., Inagi, R., Yoshihara, D., Kugita, M., Nagao, S., Shimizu, A., et al. (2017). Mitochondrial abnormality facilitates cyst formation in autosomal dominant polycystic kidney disease. Mol. Cell Biol. 37:e00337-17.

Ito, M., Tanaka, T., Ishii, T., Wakashima, T., Fukui, K., and Nangaku, M. (2020). Prolyl hydroxylase inhibition protects the kidneys from ischemia via upregulation of glycogen storage. Kidney Int. 97, 687-701. doi: 10.1016/j.kint. 2019.10.020

Jha, J. C., Gray, S. P., Barit, D., Okabe, J., El-Osta, A., Namikoshi, T., et al. (2014). Genetic targeting or pharmacologic inhibition of NADPH oxidase nox4 provides renoprotection in long-term diabetic nephropathy. J. Am. Soc. Nephrol. 25, 1237-1254. doi: 10.1681/asn.2013070810

Jia, P., Wu, X., Pan, T., Xu, S., Hu, J., and Ding, X. (2019). Uncoupling protein 1 inhibits mitochondrial reactive oxygen species generation and alleviates acute kidney injury. EBioMedicine 49, 331-340. doi: 10.1016/j.ebiom.2019. 10.023

Jiang, L., Qiu, W., Zhou, Y., Wen, P., Fang, L., Cao, H., et al. (2013). A microRNA$30 \mathrm{e} / \mathrm{mitoch}$ ndrial uncoupling protein 2 axis mediates TGF-betal-induced tubular epithelial cell extracellular matrix production and kidney fibrosis. Kidney Int. 84, 285-296. doi: 10.1038/ki.2013.80

Jiang, M., Wang, C. Y., Huang, S., Yang, T., and Dong, Z. (2009). Cisplatin-induced apoptosis in p53-deficient renal cells via the intrinsic mitochondrial pathway. Am. J. Physiol. Renal Physiol. 296, F983-F993.

Jornayvaz, F. R., and Shulman, G. I. (2010). Regulation of mitochondrial biogenesis. Essays Biochem. 47, 69-84.

Kameyama, Y., and Gemba, M. (1991). Cisplatin-induced injury to calcium uptake by mitochondria in glutathione-depleted slices of rat kidney cortex. Jpn. J. Pharmacol. 55, 174-176. doi: 10.1254/jjp.55.174

Kamezaki, M., Kusaba, T., Komaki, K., Fushimura, Y., Watanabe, N., Ikeda, K. et al. (2018). Comprehensive renoprotective effects of ipragliflozin on early diabetic nephropathy in mice. Sci. Rep. 8:4029.

Karpati, G., Carpenter, S., Engel, A. G., Watters, G., Allen, J., Rothman, S., et al. (1975). The syndrome of systemic carnitine deficiency. Clinical, morphologic, biochemical, and pathophysiologic features. Neurology 25, 16-24. doi: 10.1212/ wnl.25.1.16

Katsoulieris, E., Mabley, J. G., Samai, M., Sharpe, M. A., Green, I. C., and Chatterjee, P. K. (2010). Lipotoxicity in renal proximal tubular cells: relationship between endoplasmic reticulum stress and oxidative stress pathways. Free Radic. Biol. Med. 48, 1654-1662. doi: 10.1016/j.freeradbiomed.2010.03.021

Kestenbaum, B., Gamboa, J., Liu, S., Ali, A. S., Shankland, E., Jue, T., et al. (2020). Impaired skeletal muscle mitochondrial bioenergetics and physical performance in chronic kidney disease. JCI Insight 5:e133289.

Kikuchi, H., Sasaki, E., Nomura, N., Mori, T., Minamishima, Y. A., Yoshizaki, Y. et al. (2019). Failure to sense energy depletion may be a novel therapeutic target in chronic kidney disease. Kidney Int. 95, 123-137. doi: 10.1016/j.kint.2018. 08.030

Kim, J. W., Tchernyshyov, I., Semenza, G. L., and Dang, C. V. (2006). HIF-1mediated expression of pyruvate dehydrogenase kinase: a metabolic switch required for cellular adaptation to hypoxia. Cell Metab. 3, 177-185. doi: 10. 1016/j.cmet.2006.02.002

Kitaoka, Y., Tamura, Y., Takahashi, K., Takeda, K., Takemasa, T., and Hatta, H. (2019). Effects of Nrf2 deficiency on mitochondrial oxidative stress in aged skeletal muscle. Physiol. Rep. 7:e13998. doi: 10.14814/phy2.13998

Klein, K. I., Wang, M. S., Torikai, S., Davidson, W., and Kurokawa, K. (1980). Substrate oxidation by defined single nephron segments of rat kidney. Int. J. Biochem. 12, 53-54. doi: 10.1016/0020-711x(80)90041-5

Lamon, S., and Russell, A. P. (2013). The role and regulation of erythropoietin (EPO) and its receptor in skeletal muscle: how much do we really know? Front. Physiol. 4:176. doi: 10.3389/fphys.2013.00176

Lan, R., Geng, H., Singha, P. K., Saikumar, P., Bottinger, E. P., Weinberg, J. M., et al. (2016). Mitochondrial pathology and glycolytic shift during proximal tubule atrophy after ischemic AKI. J. Am. Soc. Nephrol. 27, 3356-3367. doi: 10.1681/asn.2015020177

Lee, J. B., and Peterhm. (1969). Effect of oxygen tension on glucose metabolism in rabbit kidney cortex and medulla. Am. J. Physiol. 217, 1464-1471. doi: 10.1152/ajplegacy.1969.217.5.1464

Lee, J. B., Vance, V. K., and Cahill, G. F. Jr. (1962). Metabolism of C14-labeled substrates by rabbit kidney cortex and medulla. Am. J. Physiol. 203, 27-36. doi: 10.1152/ajplegacy.1962.203.1.27

Levy, M., and Feingold, J. (2000). Estimating prevalence in single-gene kidney diseases progressing to renal failure. Kidney Int. 58, 925-943. doi: 10.1046/j. 1523-1755.2000.00250.x

Li, T., and Chen, Z. J. (2018). The cGAS-cGAMP-STING pathway connects DNA damage to inflammation, senescence, and cancer. J. Exp. Med. 215, 1287-1299. doi: 10.1084/jem.20180139

Lira, V. A., Benton, C. R., Yan, Z., and Bonen, A. (2010). PGC-1alpha regulation by exercise training and its influences on muscle function and insulin sensitivity. Am. J. Physiol. Endocrinol. Metab. 299, E145-E161.

Liu, C., Gidlund, E. K., Witasp, A., Qureshi, A. R., Soderberg, M., Thorell, A., et al. (2019). Reduced skeletal muscle expression of mitochondrial-derived peptides humanin and MOTS-C and Nrf2 in chronic kidney disease. Am. J. Physiol. Renal Physiol. 317, F1122-F1131.

Liu, M., Reddy, N. M., Higbee, E. M., Potteti, H. R., Noel, S., Racusen, L., et al. (2014). The Nrf2 triterpenoid activator, CDDO-imidazolide, protects kidneys from ischemia-reperfusion injury in mice. Kidney Int. 85, 134-141. doi: 10. 1038/ki.2013.357 
Lv, M., Wang, C., Li, F., Peng, J., Wen, B., Gong, Q., et al. (2017). Structural insights into the recognition of phosphorylated FUNDC1 by LC3B in mitophagy. Protein Cell 8, 25-38. doi: 10.1007/s13238-016-0328-8

Maekawa, H., Inoue, T., Ouchi, H., Jao, T. M., Inoue, R., Nishi, H., et al. (2019). Mitochondrial Damage Causes Inflammation via cGAS-STING Signaling in Acute Kidney Injury. Cell Rep. 29, 1261-1273.e6.

Mason, S. D., Howlett, R. A., Kim, M. J., Olfert, I. M., Hogan, M. C., McNulty, W., et al. (2004). Loss of skeletal muscle HIF-1alpha results in altered exercise endurance. PLoS Biol. 2:e288. doi: 10.1371/journal.pbio.0020288

Mochizuki, T., Wu, G., Hayashi, T., Xenophontos, S. L., Veldhuisen, B., Saris, J. J., et al. (1996). PKD2, a gene for polycystic kidney disease that encodes an integral membrane protein. Science 272, 1339-1342. doi: 10.1126/science.272. 5266.1339

Moorthi, R. N., and Avin, K. G. (2017). Clinical relevance of sarcopenia in chronic kidney disease. Curr. Opin. Nephrol. Hypertens 26, 219-228. doi: 10.1097/mnh. 0000000000000318

Nagasu, H., Sogawa, Y., Kidokoro, K., Itano, S., Yamamoto, T., Satoh, M., et al. (2019). Bardoxolone methyl analog attenuates proteinuria-induced tubular damage by modulating mitochondrial function. FASEB J. 33, 12253-12263. doi: 10.1096/fj.201900217r

Nambu, H., Takada, S., Fukushima, A., Matsumoto, J., Kakutani, N., Maekawa, S., et al. (2020). Empagliflozin restores lowered exercise endurance capacity via the activation of skeletal muscle fatty acid oxidation in a murine model of heart failure. Eur. J. Pharmacol. 866:172810. doi: 10.1016/j.ejphar.2019.172810

Nangaku, M., Kanda, H., Takama, H., Ichikawa, T., Hase, H., and Akizawa, T. (2020). Randomized clinical trial on the effect of bardoxolone methyl on GFR in diabetic kidney disease patients (TSUBAKI Study). Kidney Int. Rep. 5, 879-890. doi: 10.1016/j.ekir.2020.03.030

Nauli, S. M., Alenghat, F. J., Luo, Y., Williams, E., Vassilev, P., Li, X., et al. (2003). Polycystins 1 and 2 mediate mechanosensation in the primary cilium of kidney cells. Nat. Genet. 33, 129-137. doi: 10.1038/ng1076

Neitemeier, S., Dolga, A. M., Honrath, B., Karuppagounder, S. S., Alim, I., Ratan, R. R., et al. (2016). Inhibition of HIF-prolyl-4-hydroxylases prevents mitochondrial impairment and cell death in a model of neuronal oxytosis. Cell Death Dis. 7:e2214. doi: 10.1038/cddis.2016.107

Nishi, H., Higashihara, T., and Inagi, R. (2019). Lipotoxicity in kidney, heart, and skeletal muscle dysfunction. Nutrients 11:1664. doi: 10.3390/nu11071664

Nishi, H., Takemura, K., Higashihara, T., and Inagi, R. (2020). Uremic sarcopenia: clinical evidence and basic experimental approach. Nutrients 12:E1814.

Nishikawa, M., Ishimori, N., Takada, S., Saito, A., Kadoguchi, T., Furihata, T., et al. (2015). AST-120 ameliorates lowered exercise capacity and mitochondrial biogenesis in the skeletal muscle from mice with chronic kidney disease via reducing oxidative stress. Nephrol. Dial. Transplant. 30, 934-942. doi: 10.1093/ ndt/gfv103

Padovano, V., Kuo, I. Y., Stavola, L. K., Aerni, H. R., Flaherty, B. J., Chapin, H. C., et al. (2017). The polycystins are modulated by cellular oxygen-sensing pathways and regulate mitochondrial function. Mol. Biol. Cell 28, 261-269. doi: 10.1091/mbc.e16-08-0597

Palou, A., Pico, C., Bonet, M. L., and Oliver, P. (1998). The uncoupling protein, thermogenin. Int. J. Biochem. Cell Biol. 30, 7-11. doi: 10.1016/s1357-2725(97) 00065-4

Papandreou, I., Cairns, R. A., Fontana, L., Lim, A. L., and Denko, N. C. (2006). HIF1 mediates adaptation to hypoxia by actively downregulating mitochondrial oxygen consumption. Cell Metab. 3, 187-197. doi: 10.1016/j.cmet.2006.01.012

Parikh, S. M., Yang, Y., He, L., Tang, C., Zhan, M., and Dong, Z. (2015). Mitochondrial function and disturbances in the septic kidney. Semin. Nephrol. 35, 108-119. doi: 10.1016/j.semnephrol.2015.01.011

Pereira, R. A., Cordeiro, A. C., Avesani, C. M., Carrero, J. J., Lindholm, B., Amparo, F. C., et al. (2015). Sarcopenia in chronic kidney disease on conservative therapy: prevalence and association with mortality. Nephrol. Dial. Transplant. 30, 1718-1725. doi: 10.1093/ndt/gfv133

Pergola, P. E., Raskin, P., Toto, R. D., Meyer, C. J., Huff, J. W., Grossman, E. B., et al. (2011). Bardoxolone methyl and kidney function in CKD with type 2 diabetes. N. Engl. J. Med. 365, 327-336.

Perkovic, V., Jardine, M. J., Neal, B., Bompoint, S., Heerspink, H. J. L., Charytan, D. M., et al. (2019). Canagliflozin and renal outcomes in type 2 diabetes and nephropathy. N. Engl. J. Med. 380, 2295-2306.
Perry, H. M., Huang, L., Wilson, R. J., Bajwa, A., Sesaki, H., Yan, Z., et al. (2018). Dynamin-related protein 1 deficiency promotes recovery from AKI. J. Am. Soc. Nephrol. 29, 194-206. doi: 10.1681/asn.2017060659

Pickrell, A. M., and Youle, R. J. (2015). The roles of PINK1, parkin, and mitochondrial fidelity in Parkinson's disease. Neuron 85, 257-273. doi: 10.1016/ j.neuron.2014.12.007

Pin, F., Busquets, S., Toledo, M., Camperi, A., Lopez-Soriano, F. J., Costelli, P., et al. (2015). Combination of exercise training and erythropoietin prevents cancer-induced muscle alterations. Oncotarget 6, 43202-43215. doi: 10.18632/ oncotarget.6439

Puigserver, P., Wu, Z., Park, C. W., Graves, R., Wright, M., and Spiegelman, B. M. (1998). A cold-inducible coactivator of nuclear receptors linked to adaptive thermogenesis. Cell 92, 829-839. doi: 10.1016/s0092-8674(00)81410-5

Qian, F. Y., Li, Z. L., Guo, Y. D., Gao, H. C., Gu, L. H., Le, K., et al. (2019). Hypoxia-inducible factor-prolyl hydroxylase inhibitor ameliorates myopathy in a mouse model of chronic kidney disease. Am J. Physiol. Renal Physiol. 317, F1265-F1273.

Raskind, J. Y., and El-Chaar, G. M. (2000). The role of carnitine supplementation during valproic acid therapy. Ann. Pharmacother. 34, 630-638. doi: 10.1345/ aph.19242

Rector, F. C. Jr. (1983). Sodium, bicarbonate, and chloride absorption by the proximal tubule. Am. J. Physiol. 244, F461-F471.

Redza-Dutordoir, M., and Averill-Bates, D. A. (2016). Activation of apoptosis signalling pathways by reactive oxygen species. Biochim. Biophys. Acta 1863, 2977-2992. doi: 10.1016/j.bbamcr.2016.09.012

Ricquier, D., Casteilla, L., and Bouillaud, F. (1991). Molecular studies of the uncoupling protein. FASEB J. 5, 2237-2242. doi: 10.1096/fasebj.5.9.1860614

Rodriguez-Segade, S., Alonso de la Pena, C., Paz, M., Novoa, D., Romero, R., Arcocha, V., et al. (1986). Carnitine concentrations in dialysed and undialysed patients with chronic renal insufficiency. Ann. Clin. Biochem. 23(Pt 6), 671-675. doi: 10.1177/000456328602300608

Ruiz, S., Pergola, P. E., Zager, R. A., and Vaziri, N. D. (2013). Targeting the transcription factor Nrf2 to ameliorate oxidative stress and inflammation in chronic kidney disease. Kidney Int. 83, 1029-1041. doi: 10.1038/ki.20 12.439

Ryan, A. S. (2020). Role of Skeletal Muscle Mitochondrial Dysfunction in CKD. Clin. J. Am. Soc. Nephrol. 15, 912-913. doi: 10.2215/cjn.08050520

Sakurauchi, Y., Matsumoto, Y., Shinzato, T., Takai, I., Nakamura, Y., Sato, M., et al. (1998). Effects of L-carnitine supplementation on muscular symptoms in hemodialyzed patients. Am. J. Kidney Dis. 32, 258-264. doi: 10.1053/ajkd.1998. v32.pm9708610

Sato, E., Mori, T., Mishima, E., Suzuki, A., Sugawara, S., Kurasawa, N., et al. (2016). Metabolic alterations by indoxyl sulfate in skeletal muscle induce uremic sarcopenia in chronic kidney disease. Sci. Rep. 6:36618.

Schrauwen, P., and Hesselink, M. K. (2004). Oxidative capacity, lipotoxicity, and mitochondrial damage in type 2 diabetes. Diabetes 53, 1412-1417. doi: 10.2337/ diabetes.53.6.1412

Schrauwen, P., Schrauwen-Hinderling, V., Hoeks, J., and Hesselink, M. K. (2010). Mitochondrial dysfunction and lipotoxicity. Biochim. Biophys. Acta 1801, 266-271.

Schulman, G., Berl, T., Beck, G. J., Remuzzi, G., Ritz, E., Arita, K., et al. (2015). Randomized placebo-controlled EPPIC Trials of AST-120 in CKD. J. Am. Soc. Nephrol. 26, 1732-1746. doi: 10.1681/asn.2014010042

Sedeek, M., Gutsol, A., Montezano, A. C., Burger, D., Nguyen Dinh Cat, A., Kennedy, C. R., et al. (2013). Renoprotective effects of a novel Nox1/4 inhibitor in a mouse model of Type 2 diabetes. Clin. Sci. 124, 191-202. doi: 10.1042/ cs20120330

Semenza, G. L. (2011). Hypoxia-inducible factor 1: regulator of mitochondrial metabolism and mediator of ischemic preconditioning. Biochim. Biophys. Acta 1813, 1263-1268. doi: 10.1016/j.bbamcr.2010.08.006

Semenza, G. L., Jiang, B. H., Leung, S. W., Passantino, R., Concordet, J. P., Maire, P., et al. (1996). Hypoxia response elements in the aldolase A, enolase 1, and lactate dehydrogenase A gene promoters contain essential binding sites for hypoxiainducible factor 1. J. Biol. Chem. 271, 32529-32537. doi: 10.1074/jbc.271.51. 32529

Sergi, D., Naumovski, N., Heilbronn, L. K., Abeywardena, M., O’Callaghan, N., Lionetti, L., et al. (2019). Mitochondrial (Dys)function and Insulin Resistance: 
from pathophysiological molecular mechanisms to the impact of diet. Front. Physiol. 10:532. doi: 10.3389/fphys.2019.00532

Shankland, S. J. (2006). The podocyte's response to injury: role in proteinuria and glomerulosclerosis. Kidney Int. 69, 2131-2147. doi: 10.1038/sj.ki.5000410

Shimizu, A., and Yamanaka, N. (1993). Apoptosis and cell desquamation in repair process of ischemic tubular necrosis. Virchows Arch. B Cell Pathol. Incl. Mol. Pathol. 64, 171-180. doi: 10.1007/bf02915110

Siami, G., Clinton, M. E., Mrak, R., Griffis, J., and Stone, W. (1991). Evaluation of the effect of intravenous L-carnitine therapy on function, structure and fatty acid metabolism of skeletal muscle in patients receiving chronic hemodialysis. Nephron 57, 306-313. doi: 10.1159/000186280

Simon, N., and Hertig, A. (2015). Alteration of fatty acid oxidation in tubular epithelial cells: from acute kidney injury to renal fibrogenesis. Front. Med. 2:52. doi: 10.3389/fmed.2015.00052

Sinkeler, S. J., Kwakernaak, A. J., Bakker, S. J., Shahinfar, S., Esmatjes, E., de Zeeuw, D., et al. (2013). Creatinine excretion rate and mortality in type 2 diabetes and nephropathy. Diabetes Care 36, 1489-1494. doi: 10.2337/dc12-1545

Son, D., Kojima, I., Inagi, R., Matsumoto, M., Fujita, T., and Nangaku, M. (2008). Chronic hypoxia aggravates renal injury via suppression of $\mathrm{Cu} / \mathrm{Zn}-\mathrm{SOD}$ : a proteomic analysis. Am. J. Physiol. Renal Physiol. 294, F62-F72.

Sourris, K. C., Harcourt, B. E., Tang, P. H., Morley, A. L., Huynh, K., Penfold, S. A., et al. (2012). Ubiquinone (coenzyme Q10) prevents renal mitochondrial dysfunction in an experimental model of type 2 diabetes. Free Radic. Biol. Med. 52, 716-723. doi: 10.1016/j.freeradbiomed.2011.11.017

Stenvinkel, P., and Alvestrand, A. (2002). Inflammation in end-stage renal disease: sources, consequences, and therapy. Semin. Dial. 15, 329-337. doi: 10.1046/j. 1525-139x.2002.00083.x

Stewart, V. C., and Heales, S. J. (2003). Nitric oxide-induced mitochondrial dysfunction: implications for neurodegeneration. Free Radic. Biol. Med. 34, 287-303. doi: 10.1016/s0891-5849(02)01327-8

Stoyanoff, T. R., Todaro, J. S., Aguirre, M. V., Zimmermann, M. C., and Brandan, N. C. (2014). Amelioration of lipopolysaccharide-induced acute kidney injury by erythropoietin: involvement of mitochondria-regulated apoptosis. Toxicology 318, 13-21. doi: 10.1016/j.tox.2014.01.011

Susnow, N., Zeng, L., Margineantu, D., and Hockenbery, D. M. (2009). Bcl-2 family proteins as regulators of oxidative stress. Semin. Cancer Biol. 19, 42-49. doi: 10.1016/j.semcancer.2008.12.002

Suzuki, T., Furusato, M., Takasaki, S., and Ishikawa, E. (1975). Giant mitochondria in the epithelial cells of the proximal convoluted tubules of diseased human kidneys. Lab. Invest. 33, 578-590.

Takagi, S., Li, J., Takagaki, Y., Kitada, M., Nitta, K., Takasu, T., et al. (2018). Ipragliflozin improves mitochondrial abnormalities in renal tubules induced by a high-fat diet. J Diabetes Investig. 1025-1032. doi: 10.1111/jdi.12802

Tamaki, M., Miyashita, K., Wakino, S., Mitsuishi, M., Hayashi, K., and Itoh, H. (2014). Chronic kidney disease reduces muscle mitochondria and exercise endurance and its exacerbation by dietary protein through inactivation of pyruvate dehydrogenase. Kidney Int. 85, 1330-1339. doi: 10.1038/ki.2013.473

Tanaka, T., Kojima, I., Ohse, T., Inagi, R., Miyata, T., Ingelfinger, J. R., et al. (2005). Hypoxia-inducible factor modulates tubular cell survival in cisplatin nephrotoxicity. Am. J. Physiol. Renal Physiol. 289, F1123F1133.

Tang, C., Han, H., Liu, Z., Liu, Y., Yin, L., Cai, J., et al. (2019). Activation of BNIP3mediated mitophagy protects against renal ischemia-reperfusion injury. Cell Death Dis. 10:677.

Tang, C., Han, H., Yan, M., Zhu, S., Liu, J., Liu, Z., et al. (2018). PINK1PRKN/PARK2 pathway of mitophagy is activated to protect against renal ischemia-reperfusion injury. Autophagy 14, 880-897. doi: 10.1080/15548627. 2017.1405880

The European Polycystic Kidney Disease Consortium (1994). The polycystic kidney disease 1 gene encodes a $14 \mathrm{~kb}$ transcript, and lies within a duplicated region on chromosome 16. Cell 77, 881-894. doi: 10.1016/0092-8674(94)901376

Thome, T., Salyers, Z. R., Kumar, R. A., Hahn, D., Berru, F. N., Ferreira, L. F., et al. (2019). Uremic metabolites impair skeletal muscle mitochondrial energetics through disruption of the electron transport system and matrix dehydrogenase activity. Am. J. Physiol. Cell Physiol. 317, C701-C713.

Toescu, E. C. (2005). Normal brain ageing: models and mechanisms. Philos. Trans. R. Soc. Lond. B Biol. Sci. 360, 2347-2354. doi: 10.1098/rstb.2005.1771
Uruno, A., Yagishita, Y., Katsuoka, F., Kitajima, Y., Nunomiya, A., Nagatomi, R., et al. (2016). Nrf2-mediated regulation of skeletal muscle glycogen metabolism. Mol. Cell. Biol. 36, 1655-1672. doi: 10.1128/mcb. 01095-15

Vallon, V., and Thomson, S. C. (2020). The tubular hypothesis of nephron filtration and diabetic kidney disease. Nat. Rev. Nephrol. 16, 317-336. doi: 10.1038/ s41581-020-0256-y

van Tienen, F. H., Lindsey, P. J., van der Kallen, C. J., and Smeets, H. J. (2010). Prolonged Nrfl overexpression triggers adipocyte inflammation and insulin resistance. J. Cell. Biochem. 111, 1575-1585. doi: 10.1002/jcb.22889

Virbasius, J. V., and Scarpulla, R. C. (1994). Activation of the human mitochondrial transcription factor A gene by nuclear respiratory factors: a potential regulatory link between nuclear and mitochondrial gene expression in organelle biogenesis. Proc. Natl. Acad. Sci. U.S.A. 91, 1309-1313. doi: 10.1073/pnas.91.4. 1309

Wakabayashi, J., Zhang, Z., Wakabayashi, N., Tamura, Y., Fukaya, M., Kensler, T. W., et al. (2009). The dynamin-related GTPase Drp1 is required for embryonic and brain development in mice. J. Cell Biol. 186, 805-816. doi: $10.1083 /$ jcb. 200903065

Wakabayashi, T. (2002). Megamitochondria formation - physiology and pathology. J. Cell. Mol. Med. 6, 497-538. doi: 10.1111/j.1582-4934.2002.tb00452.x

Wang, L., Jia, Y., Rogers, H., Suzuki, N., Gassmann, M., Wang, Q., et al. (2013). Erythropoietin contributes to slow oxidative muscle fiber specification via PGC1alpha and AMPK activation. Int. J. Biochem. Cell Biol. 45, 1155-1164. doi: 10.1016/j.biocel.2013.03.007

Wang, Y., Cai, J., Tang, C., and Dong, Z. (2020). Mitophagy in acute kidney injury and kidney repair. Cells 9:338. doi: 10.3390/cells9020338

Waterham, H. R., Koster, J., van Roermund, C. W., Mooyer, P. A., Wanders, R. J., and Leonard, J. V. (2007). A lethal defect of mitochondrial and peroxisomal fission. N. Engl. J. Med. 356, 1736-1741. doi: 10.1056/nejmoa064436

Watson, E. L., Baker, L. A., Wilkinson, T. J., Gould, D. W., Graham-Brown, M. P. M., Major, R. W., et al. (2020). Reductions in skeletal muscle mitochondrial mass are not restored following exercise training in patients with chronic kidney disease. FASEB J. 34, 1755-1767. doi: 10.1096/fj.201901936rr

Wei, Q., Xiao, X., Fogle, P., and Dong, Z. (2014). Changes in metabolic profiles during acute kidney injury and recovery following ischemia/reperfusion. PLoS One 9:e106647. doi: 10.1371/journal.pone.0106647

Weidemann, M. J., and Krebs, H. A. (1969). The fuel of respiration of rat kidney cortex. Biochem. J. 112, 149-166. doi: 10.1042/bj1120149

Weinberg, J. M. (2006). Lipotoxicity. Kidney Int. 70, 1560-1566.

Weisiger, R. A., and Fridovich, I. (1973). Mitochondrial superoxide simutase. Site of synthesis and intramitochondrial localization. J. Biol. Chem. 248, 4793-4796.

Wu, Z., Puigserver, P., Andersson, U., Zhang, C., Adelmant, G., Mootha, V., et al. (1999). Mechanisms controlling mitochondrial biogenesis and respiration through the thermogenic coactivator PGC-1. Cell 98, 115-124. doi: 10.1016/ s0092-8674(00)80611-x

Xu, C., Kasimumali, A., Guo, X., Lu, R., Xie, K., Zhu, M., et al. (2020). Reduction of mitochondria and up regulation of pyruvate dehydrogenase kinase 4 of skeletal muscle in patients with chronic kidney disease. Nephrology 25, 230-238. doi: $10.1111 /$ nep. 13606

Yamamoto, T., Takabatake, Y., Takahashi, A., Kimura, T., Namba, T., Matsuda, J., et al. (2017). High-fat diet-induced lysosomal dysfunction and impaired autophagic flux contribute to lipotoxicity in the kidney. J. Am. Soc. Nephrol. 28, 1534-1551. doi: 10.1681/asn.2016070731

Yang, M., Li, C., and Sun, L. (2020). Mitochondria-associated membranes (MAMs): a novel therapeutic target for treating metabolic syndrome. Curr. Med. Chem. doi: 10.2174/0929867327666200212100644 [Epub ahead of print].

Yang, M., Zhao, L., Gao, P., Zhu, X., Han, Y., Chen, X., et al. (2019). DsbA-L ameliorates high glucose induced tubular damage through maintaining MAM integrity. EBioMedicine 43, 607-619. doi: 10.1016/j.ebiom.2019.04.044

Yang, X., Yan, X., Yang, D., Zhou, J., Song, J., and Yang, D. (2018). Rapamycin attenuates mitochondrial injury and renal tubular cell apoptosis in experimental contrast-induced acute kidney injury in rats. BioSci. Rep. 38:BSR201 80876.

Zhan, M., Usman, I. M., Sun, L., and Kanwar, Y. S. (2015). Disruption of renal tubular mitochondrial quality control by Myo-inositol oxygenase in diabetic kidney disease. J. Am. Soc. Nephrol. 26, 1304-1321. doi: 10.1681/asn. 2014050457 
Zhang, H., Bosch-Marce, M., Shimoda, L. A., Tan, Y. S., Baek, J. H., Wesley, J. B., et al. (2008). Mitochondrial autophagy is an HIF-1-dependent adaptive metabolic response to hypoxia. J. Biol. Chem. 283, 10892-10903. doi: 10.1074/ jbc.m800102200

Zhang, J., and Ney, P. A. (2008). NIX induces mitochondrial autophagy in reticulocytes. Autophagy 4, 354-356. doi: 10.4161/auto.5552

Zhang, J., and Ney, P. A. (2009). Role of BNIP3 and NIX in cell death, autophagy, and mitophagy. Cell Death Differ. 16, 939-946. doi: 10.1038/cdd.2009.16

Zhang, W., Siraj, S., Zhang, R., and Chen, Q. (2017). Mitophagy receptor FUNDC1 regulates mitochondrial homeostasis and protects the heart from I/R injury. Autophagy 13, 1080-1081. doi: 10.1080/15548627.2017.1300224

Zhao, C., Chen, Z., Xu, X., An, X., Duan, S., Huang, Z., et al. (2017). Pink1/Parkinmediated mitophagy play a protective role in cisplatin induced renal tubular epithelial cells injury. Exp. Cell Res. 350, 390-397. doi: 10.1016/j.yexcr.2016. 12.015
Zhao, X. F., Liu, Y. H., Han, Z. M., and Xu, Y. U. (2015). Effect of erythropoietin on the expression of dynamin-related protein-1 in rat renal interstitial fibrosis. Exp. Ther. Med. 9, 2065-2071. doi: 10.3892/etm.20 15.2419

Conflict of Interest: The authors declare that the research was conducted in the absence of any commercial or financial relationships that could be construed as a potential conflict of interest.

Copyright (c) 2020 Takemura, Nishi and Inagi. This is an open-access article distributed under the terms of the Creative Commons Attribution License (CC BY). The use, distribution or reproduction in other forums is permitted, provided the original author(s) and the copyright owner(s) are credited and that the original publication in this journal is cited, in accordance with accepted academic practice. No use, distribution or reproduction is permitted which does not comply with these terms. 